УДК 536.24:533

\title{
ОСОБЕННОСТИ ТЕЧЕНИЯ В ЦИЛИНДРИЧЕСКИХ ГОРЕЛОЧНЫХ УСТРОЙСТВАХ С ПЛАСТИНЧАТЫМИ ТУРБУЛИЗАТОРАМИ ПОТОКА
}

\author{
Фиалко Н.М., член-корреспондент НАН Украины, Шеренковский Ю.В., канд. техн. наук, \\ Меранова Н.О., канд. техн. наук, Тимощенко А.Б., Майсон Н.В.
}

Институт технической теплофизики НАН Украины, ул. Желябова, 2а, Киев, 03057, Украина

Наводяться дані комп'ютерного моделювання течії палива і окислювача в циліндричних пальникових пристроях 3 пластинчастими турбулізаторами потоку на зривних кромках стабілізаторів полум'я. Аналізуються результати досліджень за умови наявності і відсутності турбулізаторів в пальниках, що розглядаються. Представлено дані зіставлення характеристик течії для циліндричних пальників різної потужності (від 30 до 200 кВт).

Библ. 13 , рис. 6, табл. 1.
Приводятся данные компьютерного моделирования течения топлива и окислителя в цилиндрических горелочных устройствах с пластинчатыми турбулизаторами потока на срывных кромках стабилизаторов пламени. Анализируются результаты исследований, отвечающих условиям наличия и отсутствия турбулизаторов в рассматриваемых горелках. Представлены данные сопоставления характеристик течения для цилиндрических горелок различной мощности (от 30 до 200 кВт).
The data computer simulation of fuel and oxidizer flow in the cylindrical burner devices with plate vortex generators of flow on the shear edges of the flame stabilizers are given. The research results that meet the conditions of presence and absence of vortex generators in these burners are analyzed. The data comparing the flow characteristics for cylindrical burners of various capacities (from 30 to $200 \mathrm{~kW}$ ) are presented.

Ключевые слова: турбулизаторы потока, цилиндрические горелочные устройства, компьютерное моделирование, интенсивность турбулентности.

$B_{T}$ - ширина турбулизатора;

$k_{f}$ - коэффициент загромождения турбулизаторами проходного сечения канала;

$L_{p}$ - длина зоны рециркуляции;

$N_{\Gamma}^{p}$ - мощность горелочного устройства;

$I$ - интенсивность турбулентности;

$T$ - температура;

$U$ - скорость;

$U$ ' - среднеквадратичные значения пульсаций скорости;

$x$ - расстояние по потоку от передней кромки стабили-

\section{Введение}

Важность исследования характеристик течения топлива и окислителя в горелочных устройствах стабилизаторного типа обусловлена тем, что они в большой мере определяют закономерности смесеобразования, стабилизации пламени и выгорания топлива. Особый интерес представляет изучение структуры течения при использовании в стабилизаторных горелках различных турбулизаторов потока, призванных интенсифицировать протекание в них тепломассообменных процессов. К эффективным средствам турбулизации потока в горелочных устройствах стабилизаторного типа относится установка пластинчатых элементов на затупленной задней кромке стабилизаторов.

Принимая во внимание тенденцию ко все более широкому распространению в энергетической практике цилиндрических стабилизаторных горелочных устройств, актуальным является исследование особенностей течения в таких устройствах с пластинчатыми турбулизаторами потока. При этом представляется важ- затора;

$\alpha$ - коэффициент избытка воздуха.

\section{Сокращения:}

RANS (Reynolds Averaged Navier-Stokes) - методы, базирующиеся на осредненных по Рейнольдсу уравнениях Навье-Стокса.

\section{Индексы: \\ в - воздух; \\ $\Gamma-$ газ.}

ным проведение соответствующих исследований для горелок данного класса различной мощности.

\section{1. Анализ последних исследований и публикаций}

В последнее время заметно возросло количество исследований, посвященных изучению закономерностей протекания процессов переноса в стабилизаторных горелочных устройствах (см., например, [1-5]). При этом в ряде работ рассматриваются возможности применения различных средств интенсификации данных процессов [6-10]. Так, в [9] анализируются эффекты влияния нишевых полостей, расположенных на боковых поверхностях стабилизаторов, на характеристики рабочих процессов горелочных устройств. В [10] приводятся результаты исследований, касающихся использования для интенсификации массообмена в зоне рециркуляции за стабилизатором разноименной закрутки воздушного потока, обтекающего стабилизатор. В этой же работе рассматриваются эффекты интенсификации процессов горения за счет установки перед стабилизатором турбулизирующих решеток. Однако для цилин- 
дрических горелочных устройств работы, посвященные интенсификации тепломассопереноса, являются весьма немногочисленными и не охватывают широкий круг вопросов, актуальных в энергетической практике [11-12].

Ввиду изложенного важным представляется проведение исследований по изучению возможности турбулизации течения топлива и окислителя в цилиндрических стабилизаторных горелочных устройствах за счет применения пластинчатых элементов.

\section{2. Формулировка цели статьи}

Цель работы состоит в установлении закономерностей течения топлива и окислителя в цилиндрических горелочных устройствах стабилизаторного типа с пластинчатыми турбулизаторами потока, расположенными на затупленных задних кромках стабилизаторов.

\section{3. Особенности постановки задачи}

Исследованию подлежали характеристики течения топлива и окислителя в цилиндрическом горелочном устройстве, представляющем собой круглый канал с соосно расположенным в нем цилиндрическим стабилизатором пламени, на затупленной задней кромке которого установлены пластинчатые турбулизаторы потока (рис. 1). На вход цилиндрического канала 1 подается воздух, обтекающий цилиндрический стабилизатор 2. Подлежащий сжиганию газ через систему круглых отверстий 3 на боковой поверхности стабилизатора подается в сносящий поток воздуха.

Исследования проводились на основе математического моделирования. Математическая постановка соответствующей задачи приведена в [11].

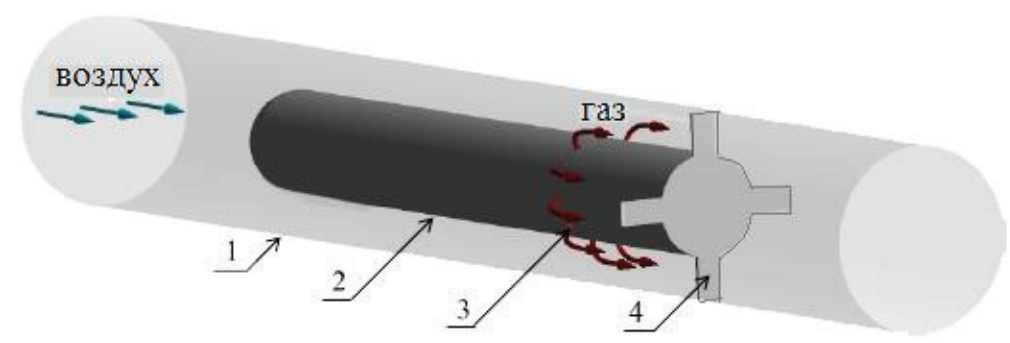

\section{Рис. 1. Схема цилиндрического горелочного устройства с пластинчатыми турбулизаторами потока на срывных кромках стабилизатора: \\ 1 - цилиндрический канал; 2 - цилиндрический стабилизатор; \\ 3-газоподающие отверстия; 4 - пластинчатые турбулизаторы потока.}

Решение задачи осуществлялось на основе RNG подхода. Для замыкания рассматриваемой системы основных операторных уравнений использовалась $\mathrm{k}-\varepsilon$ модель турбулентности.

При математическом моделировании интенсивность турбулентности воздуха на входе в цилиндрический канал $I_{B}$ и природного газа в поперечных сечениях газоподающих отверстий $I_{\Gamma}$ равнялась $3 \%$; коэффициент избытка воздуха $\alpha$ задавался равным 1,1 ; абсолютная температура газа $T_{\Gamma}$ и воздуха $T_{B}$ на входе составляла $300 \mathrm{~K}$.

Исследования проводились для типоряда горелочных устройств мощностью $N_{\Gamma}=30 ; 110 ; 155$ и 200 кВт. Основные конструктивные и режимные параметры рассматриваемого типоряда приведены в [11].

В табл. 1 даны характеристики пластинчатых турбулизаторов потока для исследуемого типоряда горелок. Ширина турбулизаторов $B$ тыбиралась из соображений, согласно которым коэффициент загромождения турбулизаторами проходного сечения канала $k_{f}$ для горелочных устройств разной мощности должен быть одинаковым и равным примерно 0,2. Толщина турбулизаторов принималась равной $1,5 \cdot 10^{-3}$ м. Что касается количества турбулизаторов, то, как видно из табл. 1, реализуется тенденция к увеличению количества стабилизаторов с повышением мощности горелочного устройства.

\section{4. Изложение основного материала}

Характерные данные компьютерных предсказаний структуры течения для типоряда цилиндрических горелочных устройств мощностью 30..200 кВт с пластинчатыми турбулизаторами потока на срывных кромках стабилизаторов приведены на рис. 2 - 6. Здесь рис. 2 - 4 иллюстрируют результаты моделирования для горелки мощностью 110 кВт, отвечающие условиям наличия и отсутствия турбулизаторов потока. Данные численных исследований для горелок различной мощности представлены на рис. 5, 6.

На рис. 2 приведена картина линий тока для горелочного устройства мощностью 110 кВт при наличии и отсутствии турбулизаторов потока. Как видно, в последнем случае имеет место одна зона рециркуляции непосредственно за торцевой поверхностью стабилизатора. При наличии же турбулизаторов за каждым из них образуется отдельная зона рециркуляции. При этом протяжённость этих зон по потоку существенно превышает соответствующую протяжённость зоны рециркуляции за торцом стабилизатора в условиях, когда на его кромках не устанавливаются турбулизаторы потока. Так, в рассматриваемых условиях величина $L$ составляет 0,116 м для зон за турбулизаторами и 0,0475 м - для зоны за торцом гладкого стабилизатора.

Как следует из полученных данных, в сопоставляе- 
мых ситуациях трехмерный характер течения обуславливается различными факторами. Так, если в случае отсутствия турбулизаторов основным источником трехмерности потока являются газовые струи, то при наличии турбулизирующих пластин - как газовые струи, так и собственно эти пластины.

Рис. 3 - 4 иллюстрирует данные компьютерного моделирования для горелок с турбулизаторами потока и без них, касающиеся поведения пульсационных составляющих скоростей. (На этих рисунках и на рис. 5 сплошные линии отвечают положению границ зон рециркуляции). Здесь, прежде всего, обращает на себя внимание тот факт, что при наличии турбулизаторов наблюдается существенно более высокий уровень пульсаций скорости в значительной части потока за стабилизатором пламени. При этом более высоким оказывается и максимальный уровень пульсаций скорости. Для сопоставляемых ситуаций эти уровни составляют соответственно $4,5 \mathrm{M} / \mathrm{c}$ и $2,8 \mathrm{~m} / \mathrm{c}$.

Существенно отличается для сравниваемых усло-

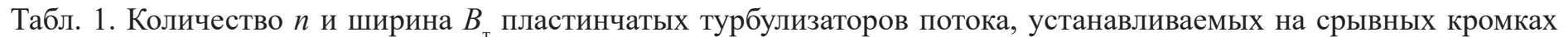
стабилизаторов пламени, для типоряда цилиндрических горелочных устройств мощностью $30 \ldots 200$ кВт

\begin{tabular}{|c|c|c|}
\hline$N_{,}, \mathrm{KBT}$ & $n$ & $B_{\tau^{\prime}}, 10^{-3} \mathrm{M}$ \\
\hline 30 & 3 & 6 \\
\hline 110 & 4 & 9 \\
\hline 155 & 5 & 9 \\
\hline 200 & 5 & 11 \\
\hline
\end{tabular}
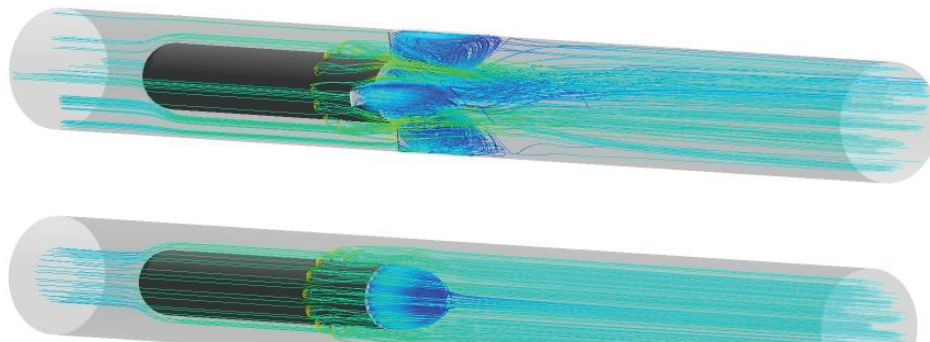

б)

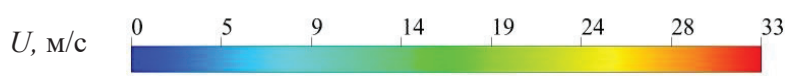

Рис. 2. Картина линий тока для цилиндрического горелочного устройства мощчностью 110 кВт при наличии (а) и отсутствии (б) турбулизаторов потока.

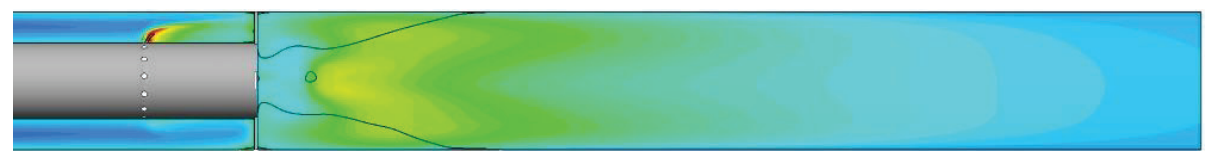

a)

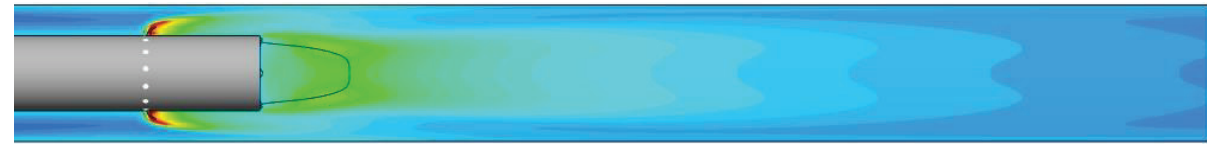

б)

$U^{\prime}, \mathrm{M} / \mathrm{c}$

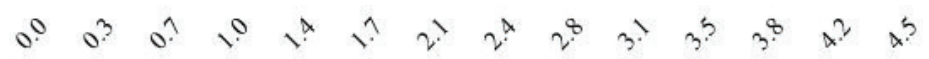

Рис. 3. Поля среднеквадратичных значений пульсаций скорости $U^{\prime}$ в продольном сечении, проходящцем через ось газоподающцх отверстий, для цилиндрического горелочного устройства моциностью 110 кВт при наличии (а) и отсутствии (б) турбулизаторов потока. 
вий и характер полей пульсаций скорости. При отсутствии турбулизаторов зоны с повышенным уровнем пульсаций располагаются в центральной части канала, отвечающей зонам рециркуляции потока. В случае установки турбулизаторов на срывной кромке стабилизатора максимальный уровень пульсаций наблюдается на границах зон обратных токов за каждым из четырёх турбулизаторов пламени. По мере удаления от торца стабилизатора вниз по потоку границы зон повышенной турбулизации несколько размываются.

На рис. 5 представлены поля среднеквадратичных значений пульсаций скорости для цилиндрических горелочных устройств разной мощности с турбулизаторами потока. Как следует из полученных данных, количество зон рециркуляции отвечает количеству турбулизаторов потока и составляет 3, 4, 5 и 5 для горелок мощностью $30 ; 110 ; 155$ и 200 кВт. При этом зоны с повышенными уровнями пульсаций как бы следят за местоположением турбулизаторов потока. Обращает на себя внимание также тот факт, что с ростом мощности горелочного устройства зоны, отвечающие поперечным сечениям собственно струй, становятся более ярко выраженными.

Рис. 6 иллюстрирует данные об изменении интенсивности турбулентности вдоль оси следа за стабилизатором пламени для рассматриваемого типоряда горелок при наличии и отсутствии турбулизаторов потока. Как видно, для обеих рассматриваемых ситуаций указанное

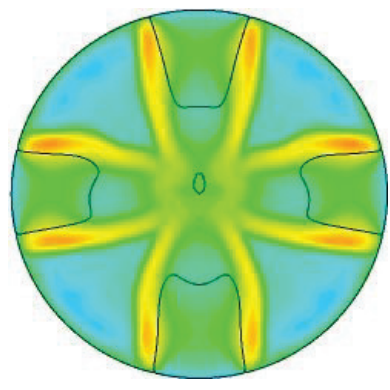

a)

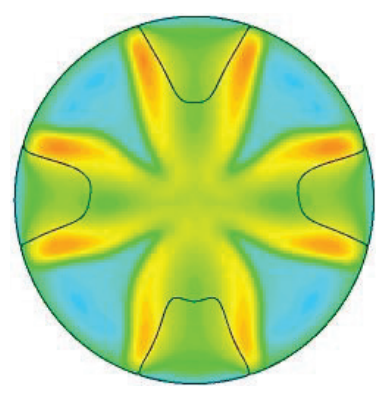

в) изменение имеет экстремальный характер. При этом на некотором удалении от срывной кромки стабилизатора, при $x>0,55$ м, наиболее низкий уровень интенсивности турбулентности отвечает горелке мощностью 30 кВт, заметно более высокий - горелке мощностью 110 кВт. Что же касается горелок мощностью 155 и 200 кВт, то здесь интенсивность турбулентности является практически одинаковой.

Согласно приведенным данным, установка турбулизаторов потока на срывной кромке стабилизатора пламени может приводить к существенному повышению интенсивности турбулентности. Данное повышение оказывается наиболее значительным вблизи торца стабилизатора в зонах, отвечающих максимуму кривой $I=f(x)$. Так, для горелки мощностью 30 кВт ввиду наличия турбулизаторов интенсивность турбулентности увеличивается более чем в 1,4 раза.

По мере удаления от торца стабилизатора пламени влияние турбулизаторов на величину интенсивности турбулентности уменьшается. Причём наиболее быстро это влияние убывает для горелки наименьшей мощности $\left(N_{г}=30\right.$ кВт). Например, при $x=0,45$ м, т. е. на расстоянии 0,2 м от торца стабилизатора пламени, благодаря установке турбулизаторов интенсивность турбулентности повышается для горелки мощностью 200 кВТ примерно на 10 \%, а для горелки мощностью 30 кВТ лишь на $5 \%$.

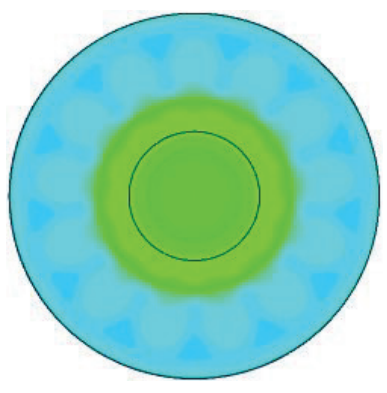

б)

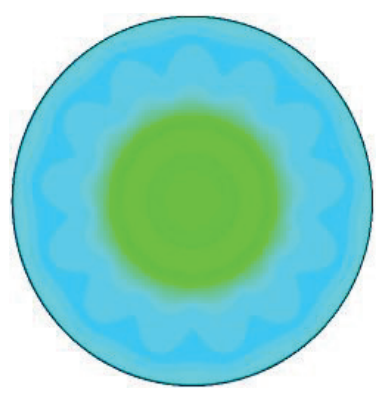

г)

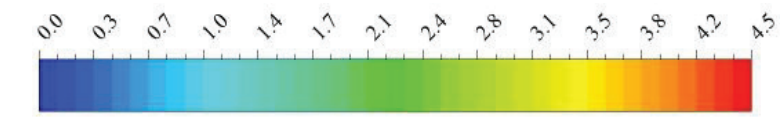

Рис. 4. Поля среднеквадратичных значений пульсаций скорости $U^{\prime}$ в поперечных сечениях $\boldsymbol{x}=0,28$ м $(a$, б) и $\boldsymbol{x}=0,3$ м $($ в, г) для горелочного устройства мощностью 110 кВт при наличии $(a$, в) и отсутствии $(\sigma, 2)$ турбулизаторов потока. 


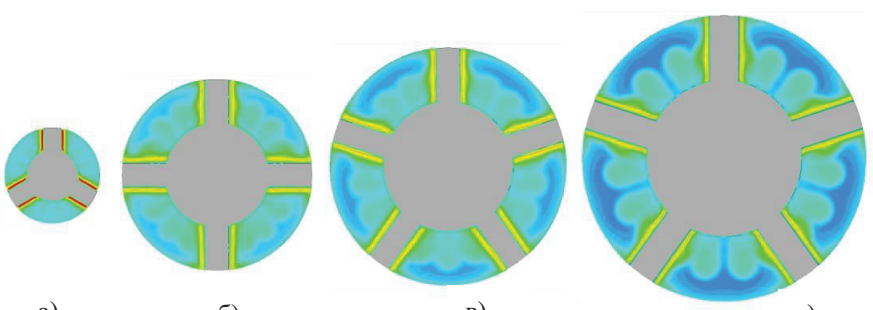

a)

б)

в)

г)

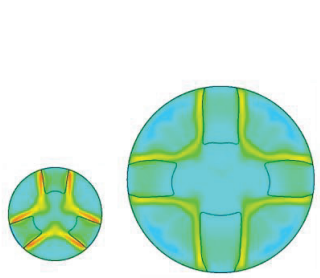

д)

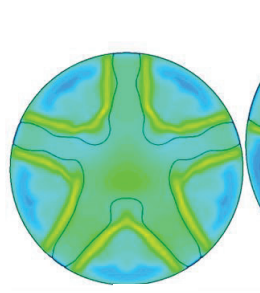

ж)

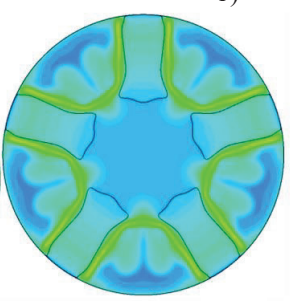

e)

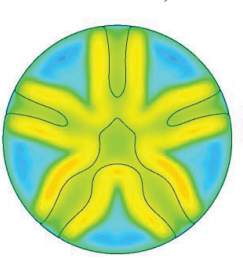

л)

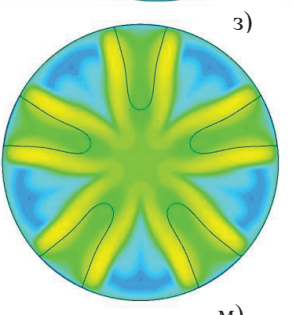

и)

К)

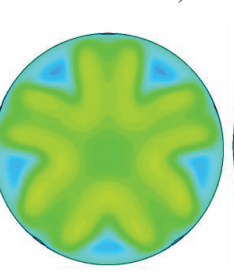

п)

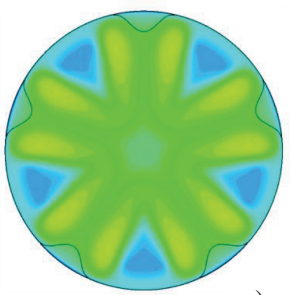

H)

o)

p)

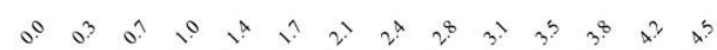

$\mathrm{u} / \mathrm{c}$

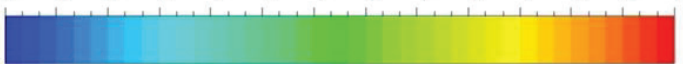

Рис. 5. Поля среднеквадратичных значений пульсаций скорости $U^{\prime}$ для цилиндрических горелочных устройств разной мощности с турбулизаторами потока: $N_{\Gamma}=30 \kappa B m(a, \delta, u, H)$;

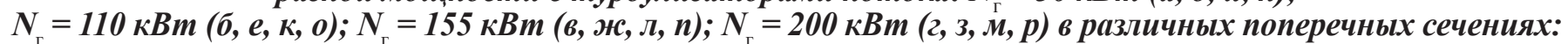

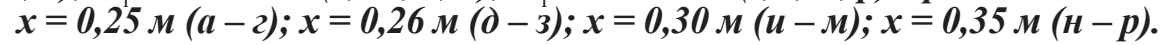

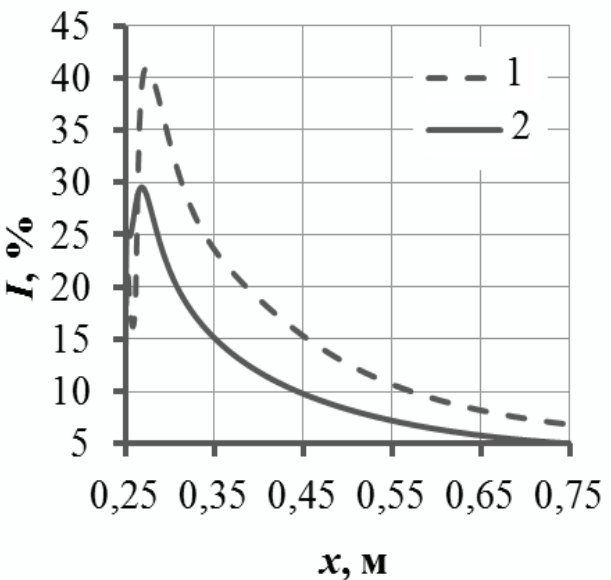

a)

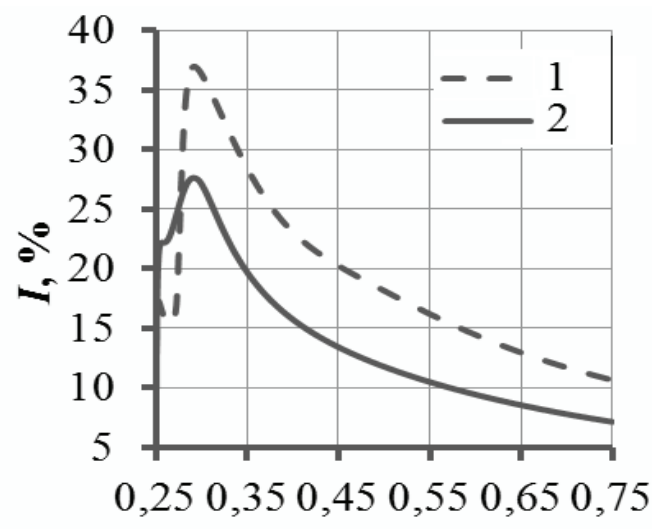

$\boldsymbol{x}, \mathbf{M}$

б) 


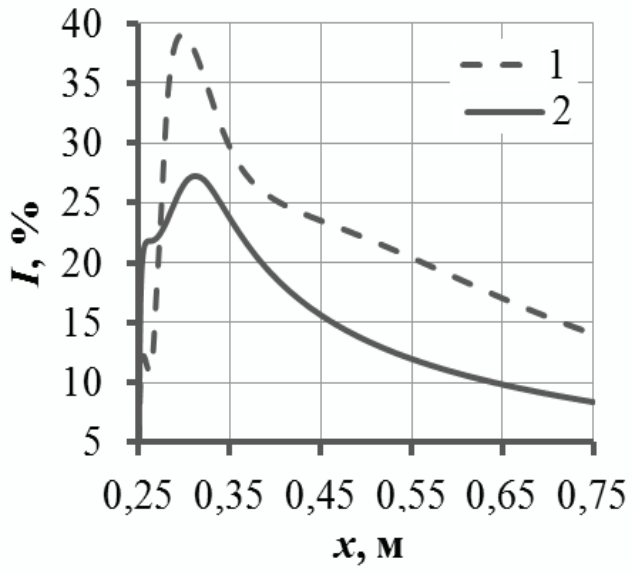

B)

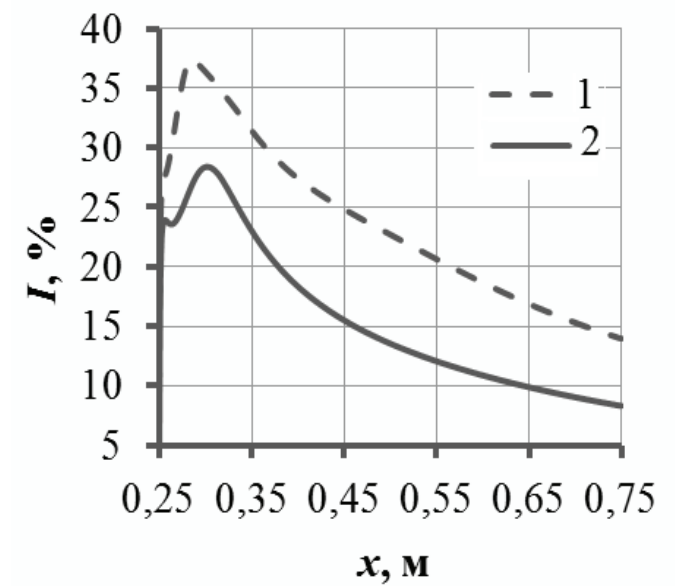

г)

\section{Рис. 6. Изменение интенсивности турбулентности вдоль оси следа за цилиндрическим стабилизатором пламени при наличии (1) и отсутствии (2) турбулизаторов потока для горелок разной мощности: a) $N_{\mathrm{r}}=30 \kappa \mathrm{Bm}$; б) $N_{\mathrm{r}}=110 \kappa \mathrm{Bm}$; в) $N_{\mathrm{r}}=155 \kappa \mathrm{Bm}$; z) $N_{\mathrm{r}}=200 \kappa \mathrm{Bm}$.}

Проведенные исследования показали также, что установка турбулизаторов потока на срывной кромке стабилизаторов пламени приводит к некоторому повышению потерь давления в горелочных устройствах. Так, для горелки мощностью 200 кВт эти потери составляют 85 и 33 Па соответственно при наличии и отсутствии турбулизаторов потока. То есть потери давления в горелочном устройстве с турбулизаторами потока остаются весьма небольшими по величине.

\section{Выводы}

1. Для типоряда цилиндрических стабилизаторных горелочных устройств мощностью от 30 до 200 кВт с пластинчатыми турбулизаторами потока на срывных кромках стабилизаторов исследованы закономерности течения топлива и окислителя.

2. Выполнен сравнительный анализ особенностей течения для цилиндрических горелочных устройств при наличии и отсутствии турбулизаторов потока. Показано, что в случае установки турбулизаторов на срывных кромках стабилизаторов пламени:

- происходит существенное изменение картины течения с образованием за каждым из турбулизаторов зон рециркуляции значительной протяженности по потоку;

- имеет место существенная турбулизация течения в значительной части потока за стабилизатором пламени; данная турбулизация в наибольшей мере проявляется вблизи границ зон рециркуляции.

- наблюдается увеличение потерь давления в горелочном устройстве, которые остаются при этом относительно небольшими по величине.

3. Проведено сопоставление характеристик течения в горелках различной мощности с турбулизаторами потока. Установлено, в частности, что с ростом мощности горелочного устройства имеет место тенденция к увеличению размеров зоны за стабилизатором пламени, в которой наблюдается заметная турбулизация потока, обусловленная наличием турбулизирующих пластин.

\section{ЛИТЕРАТУРА}

1. Triantafyllidis A. Large Eddy Simulations of forced ignition of a non-premixed bluff-body methane flame with Conditional Moment Closure / A. Triantafyllidis, E. Mastorakos, G. M. Eggels // Combustion and Flame. 2009. - Vol. 156. - P. 2328-2345.

2. Dally B.B. Measurements of no in turbulent nonpremixed flames stabilized on a bluff body / B.B. Dally, A.R. Masri, R.S. Barlow, G.J. Fiechtner, D.F. Fletcher // Twenty-Sixth Symposium (International) on Combustion/ The Combustion Institute, 1996. - P. 2191-2197.

3. Ahmed S.F. Spark ignition of turbulent nonpremixed bluff-body flames / S.F. Ahmed, R. Balachandran, T. Marchione, E. Mastorakos // Combustion and Flame. 2007. - Vol. 151. - P. 366-385.

4. Subramanian $V$. Large eddy simulation of forced ignition of an annular bluff-body burner / V. Subramanian, P. Domingo, L. Vervisch // Combustion and Flame. - 2010. Vol. 157. - P. 579-601.

5. Hua-Guang Li. A Large-Eddy-Simulation Study of Combustion Dynamics of Bluff-Body Stabilized Flames/ Hua-Guang Li, Prashant Khare, Hong-Gye Sung \& Vigor Yang // Combustion Science and Technology. - 2016. - V. 188, Issue 6. - P. 924-952.

6. Бутовський Л.С. Експериментальні дослідження структури течії у пальникових пристроях стабілізаторного типу 3 застосуванням кутових турбулізаторів потоку/ Л.С. Бутовський, Н.М. Фіалко, В.Г. Прокопов, О.А. Зарицький, Ю.В. Шеренковський, О.Б. Тимощенко //Мат. XXII межд. конф. «Проблемы экологии и эксплуатации объектов енергетики», 8-12 июня 2012 г., Ялта. - Киев, 2012. - С. 141-145.

7. Фіалко Н.М. Математичне моделювання течії та сумішоутворення в стабілізаторних пальникових пристроях 3 кутовими відкритими інтенсифікаторами горіння/ Н.М. Фіалко, Н.П. Полозенко, М.В. Майсон // 9-ая Международная научно-практическая конференция 
«Угольная теплоэнергетика: проблемы реабилитации и развития», Алушта, 19-23 сентября 2013. - С. 88-90.

8. Прокопов В.Г. Математическое моделирование сжигания топлива в микрофакельных горелочных устройствах с интенсификаторами процессов горения/ В.Г. Прокопов, Н.М. Фиалко, Ю.В. Шеренковский, С.А. Алешко, Н.О. Меранова, Н.В. Майсон, Л.С Бутовский., Е.А. Грановская, К.В. Рокитько //Мат. VIII межд. Конф. «Проблемы промышленной теплотехники, Киев, 8-11 октября 2013г. (Электронное издание).

9. Фіалко Н.М. Підвищення інтенсивності процесів переносу в циліндричному стабілізаторному пальнику шляхом застосування прямокутних кільцевих ніш/ Н.М. Фіалко, Ю.В. Шеренковський, М.В. Майсон, М.3. Абдулін, С.В. Хомук, А.О. Сніна, О.Б Тимощенко// Сборник трудов «Проблемы экологии и эксплуатации объектов энергетики». - К.: ИПЦ АЛКОН НАН Украины, 2014. - С. 122-125.

10. Грановська О.О. Удосконалення стабілізаторних пальникових пристроїв при мікрофакельному спалюванні газу/ Автореф. ... канд. техн. наук. - Київ:
НТУУ «КПІ», 2014. - 26 c.

11. Фиалко Н.М. Тепломассообменные процессы в цилиндрических горелочных устройствах с нишевыми полостями/ Н.М. Фиалко, Ю.В. Шеренковский, Н.В. Майсон, Н.О. Меранова, А.Б. Тимощенко// Промышленная теплотехника. - 2016. - №6. - С.3-13.

12. Фиалко Н.М. Закономірності течії в прямокутних кільцевих нішах циліндричних стабілізаторних пальників різної потужності / Н.М. Фіалко, М.В. Майсон, М.3. Абдулін, М.В. Ганжа, К.В. Рокитько, А.А. Озеров, Д.П. Хміль // Науковий вісник Національного університету біоресурсів і природокористування України. Серія «Техніка та енергетика АПК». - 2016. Вип. 240. - С. 69-76.

13. Фиалко Н.М. Интенсификация процессов переноса в горелочном устройстве с цилиндрическим стабилизатором пламени / Н.М. Фиалко, Ю.В. Шеренковский, Н.В. Майсон, Н.О. Меранова, Л.С. Бутовский, М.З. Абдулин, Н.П. Полозенко, А.В. Клищ, С.Н. Стрижеус, А.Б. Тимощенко // Науковий вісник НЛТУ України. - 2014. - Вип. 24.5 - С. 136-142. 


\section{FEATURES OF FLOW IN CYLINDRICAL BURNER DEVICE WITH PLATE VORTEX GENERATOR FLOW}

Fialko N.M., Sherenkovskii Ju.V., Meranova N.O., Timoshchenko A.B., Maison N.V.

Institute of Engineering Thermophysics of National Academy of Sciences of Ukraine, 2a, Zhelyabova str., Kiev, 03057, Ukraine.

The data computer simulation of fuel and oxidizer flow in the cylindrical burner devices with plate vortex generators of flow on the shear edges of the flame stabilizers are given. The research results that meet the conditions of presence and absence of vortex generators in these burners are analyzed. Effect features of the installation of vortex generator on the flow structure of fuel and oxidant, the pressure loss in the burner and so on are reported. The data comparing the flow characteristics for cylindrical burners of various capacities (from 30 to $200 \mathrm{~kW}$ ) are presented. It is noted that attaching the plates to the blunt trailing edge of cylindrical stabilizers leads to a substantial turbulence of the flow in a relatively large area over the flame stabilizer.

References 13, figures 6, tables 1.

Key words: vortex generators of flow, cylindrical burners, computer simulation, turbulence intensity.

1. A. Triantafyllidis, E. Mastorakos, G. M. Eggels. Large Eddy Simulations of forced ignition of a nonpremixed bluff-body methane flame with Conditional Moment Closure. Combustion and Flame, 2009, Vol. 156, P. 2328-2345.

2. B.B. Dally, A.R. Masri, R.S. Barlow, G.J. Fiechtner, D.F. Fletcher. Measurements of no in turbulent non-premixed flames stabilized on a bluff body. Twenty-Sixth Symposium (International) on Combustion. The Combustion Institute, 1996, P. 2191-2197.

3. S.F. Ahmed R. Balachandran, T. Marchione, E. Mastorakos. Spark ignition of turbulent nonpremixed bluff-body flames, Combustion and Flame, 2007, Vol. 151, P. 366-385.

4. V. Subramanian, P. Domingo, L. Vervisch. Large eddy simulation of forced ignition of an annular bluff-body burner. Combustion and Flame, 2010, Vol. 157, P. 579-601.

5. Hua-Guang Li, Prashant Khare, Hong-Gye Sung \& Vigor Yang. A Large-Eddy-Simulation Study of Combustion Dynamics of Bluff-Body Stabilized Flames. Combustion Science and Technology, 2016, V. 188, Issue 6, P. 924-952.

6. L.S. Butovskii, N.M. Fialko, V.G. Prokopov, O.A. Zaryckyj, Y.V. Sherenkovskyy, O.B. Tymoschenko. Eksperimentalni doslidzhennia struktury techii u palnikovih pristrojah stabilizatornogo tipu $\mathrm{z}$ zastosuvanniam kutovih ctabilizatoriv potoku [Experimental study of flow structure in burners of stabilizer type using corner vortex flow]. Mat. XXII Intl. Conf. "Problemi ekologii I ekspluatacii obektov energetiki"'Problems of Ecology and operation of energy objects], 8-12 June 2012, Yalta, Kiev, 2012, P. 141-145. (Ukr)

7. N.M. Fialko, N.P. Polozenko, N.V. Mayson. Matematichne modeliuvannia techii ta sumishoutvorennia v stabilizatornih palnikovih pristrojah z kutovimi vidkritimi intensifikatorami gorinnja [Mathematical modeling of flow and mixing in stabilizer burners with corner intensifiers open burning], 9-th International scientificpractical conference "Uholnaja teploenerhetika: problemy reabilitacii i razvitija" ["Coal heat and power engineering: Problems of Rehabilitation and Development"], Alushta, 19-23 September, 2013, P. 88-90. (Ukr)

8. V.G. Prokopov, N.M. Fialko, Y.V. Sherenkovsky, S.A. Aleshko, N.O. Meranova, N.V. Mayson, L.S. Butovsky., E.A. Granovskaya, K.V.Rokitko. Matematicheskoe modelirovanie szhiganija topliva v mikrofakelnich gorelochnih ustroystvah $\mathrm{s}$ intensifikatorami processa gorenija [Mathematical modeling of fuel combustion in microjet burners with combustion processes intensifiers]. Mat. VIII Int. Conf. "Problemy promishlennoy teplotehniki"["Problems of industrial heat engineering"], Kiev, on October 8-11, 2013. (Electronic edition). (Rus)

9. N.M. Fialko, Y.V. Sherenkovsky, M.V. Mayson, M.Z. Abdulin, S.V. Homuk, S.A. Enina, O.B. Timoshenko. Pidvischennya intensivnosti protsesiv perenosu in tsilindrichnomu stabilizatornomu palniku shlyakhov zastosuvannya pryamokutnih kiltsevih nish. Proceedings "Problemi ekologii i ekspluatacii obektov energetiki" ["Problems of ecology and exploitation of energy objects"], K, CPI ALCON NAS of Ukraine, 2014, P. 122-125. (Ukr)

10. Granovskaya A.A. Udoskonalennija stabilizatornich palnikovyh pristroiv pri mikrofakelnomu spaluvanni gazu [Improving stabilizer burners at microjet combustion of gas], Author. ... Candidate of Techn. Science, Kyiv, NTUU "KPI", 2014, 26 p. (Ukr)

11. N.M. Fialko, Y.V. Sherenkovsky, N.V. Mayson, N.O. Meranova, A.B. Timoshchenko. Teplomassoobmennie processy $\mathrm{V}$ cilindricheskih gorelochnyh ustroystvah $\mathrm{S}$ nishevymi polostiami [Heat and mass transfer processes in the cylindrical burner devices with niche cavities]. Promyshlennaja teplotehnika [Industrial heat engineering], 2016, №6, P.3-13. (Rus)

12. N.M. Fialko, N.V. Mayson, M.Z. Abdulin, N.V. Ganzha, K.V. Rokytko, A.A. Ozerov, D.P. Hmil. Zakonomirnosti techii $\mathrm{V}$ priamokutnih kilcevih nishah cilindricheskih stabilizatornih palnikiv riznoi potuzhnosti [Patterns of flow in rectangular circular niches of cylindrical stabilizer burners of different power]. Naukovyi visnik Nacionalnogo universitetubioresursiv I prirodokoristuvannia Ukrainy. Serija "Technika i energetika APK" [Scientific Bulletin of National Agriculture University of Ukraine, Series "Technology agribusiness and energy"], 2016, Issue 240, P. 69-76. (Ukr)

13. N.M. Fialko, Y.V. Sherenkovsky, N.V. Mayson, N.O. Meranova, L.S. Butovsky, M.Z. Abdulin, N.P. Polozenko, A.V. Klisch, S.N. Strizheus, A.B. Timoshchenko. Intensifikacija processov perenosa $\mathrm{v}$ gorelochnom ustroystve s cilindricheskim stabilizatorom plameni [Intensification of the transport processes in the burner with a cylindrical flame stabilizer], Naukovy Visnyk NLTU Ukrainy [Scientific Journal NLTU Ukraine], 2014, Issue 24.5, P. 136-142. (Rus)

Получено 31.01.2017 Received 31.01.2017 